DOI: $10.13037 /$ ci.vol20n44.6230

\title{
Cultura Nerd como Semiosfera: uma proposta de entendimento
}

NERD CULTURE AS SEMIOSPHERE: A PROPOSAL OF UNDERSTANDING

\author{
L Herom Vargas $^{1}$ \\ ORCID: https://orcid.org/0000-0002-7837-6740 \\ (Universidade Metodista de São Paulo, Programa de Pós-Graduação em Comunicação. São \\ Bernardo do Campo - SP, Brasil)
}

\section{Anderson Rocha ${ }^{2}$}

ORCID: https://orcid.org/0000-0001-8999-5769

(Universidade Metodista de São Paulo, Programa de Pós-Graduação em Comunicação. São

Bernardo do Campo - SP, Brasil)

\section{Resumo}

O objetivo deste artigo é apresentar a cultura nerd como sistema simbólico dinâmico, origem de identificações, ritos e práticas sociais, construído e divulgado pela cultura midiática e seus produtos quadrinhos, cinema e televisão. A argumentação está ancorada nos conceitos da Semiótica da Cultura (SC). Para isso, são propostos os seguintes passos: apresentar os principais conceitos da $\mathrm{SC}$, especialmente o de semiosfera, de Lótman; caracterizar a cultura nerd, a partir de personagens de filmes e de séries de TV; e relacionar a cultura nerd com a teoria da SC.

Palavras-chave: Cultura nerd. Semiótica da cultura. Semiosfera.

\section{Abstract}

The objective of this article is to present the nerd culture as dynamic symbolic system, origin of identifications, rites and social practices, constructed and disseminated by the media culture and its products - comics, cinema and television. The argumentation is anchored in the concepts of the Semiotics of Culture (SC). For this, the following steps are proposed: to present the main concepts of the SC, especially Lótman's concept of semiosphere; characterize the nerd culture from movies and TV series characters; and to relate the nerd culture to the SC theory.

Keywords: Nerd culture. Semiotics of culture. Semiosphere. 


\section{Introdução}

O conceito de cultura pode ser discutido por diversas áreas do conhecimento, com definições algumas vezes antagônicas. Por exemplo, a cultura como acúmulo de conhecimento traduzido nas artes e nas ciências, como formulado pelo Iluminismo ${ }^{1}$, está distante do entendimento de cultura como um conjunto de ritos e práticas sociais simbólicas proposto pelos Estudos Culturais ingleses, nos anos de 1960, no Centre for Contemporary Cultural Studies, na Universidade de Birmingham. As diversas interpretações sobre o conceito geram possibilidades de análise de objetos da criação humana também de múltiplas maneiras.

Neste artigo, trabalharemos com as ideias de que 1) a cultura está sempre em transformação, por si própria ou pela interação com elementos externos e novos que a reconfiguram, e 2) sua forma e seus sentidos estão sempre em tensão e o dinamismo é o caráter mais evidente. Ambas características norteiam a reflexão sobre a cultura nerd como uma semiosfera, baseado nos estudos da Semiótica da Cultura (SC) e nos Estudos da Escola de Tártu-Moscou (ETM). Para isso, será apresentado um breve histórico da ETM e os conceitos principais propostos pela SC. Posteriormente, retomaremos uma sucinta discussão sobre a cultura nerd e seu percurso nas mídias e, por fim, será realizada uma análise de como o nerd e seus elementos culturais se configuram como uma semiosfera, conforme foi proposto pelo semioticista russo Iuri Lótman².

\section{A Escola de Tártu-Moscou e a semiótica da cultura}

Na década de 1960, se constituiu em Tártu, na Estônia, um espaço de pensadores com ascensão soviética que buscavam entender as várias manifestações culturais. As discussões aconteceram em seminários de verão, anualmente realizados, onde as ideias propostas eram debatidas "na melhor tradição do diálogo socrático e da prática reflexiva de Santo Agostinho" (MACHADO, 2003, p. 34). O que gerou, posteriormente, publicações sobre o conteúdo das discussões.

Os estudos reuniram pesquisadores engajados pela ideia de sistematizar o entendimento sobre a cultura a partir dos referenciais da linguística, influenciados pelos legados de Roman Jakobson e Mikhail Bakhtin. Para os estudiosos, onde há comunicação

\footnotetext{
${ }^{1}$ Por exemplo, ver as críticas de T. Adorno (1989) à "música ligeira", alienante e superficial, frente à tradição das músicas de vanguarda.

${ }^{2}$ Iuri Mikhailovich Lótman (São Petersburgo, Rússia, 1922 - Tártu, Estônia, 1993).
} 
existe também um sistema linguístico, portanto, de signos. Dentre esses sistemas de signos estão o gestual, os sistemas sonoros, a arquitetura, o teatro etc. O intuito era compreender o conjunto de práticas humanas que denominamos cultura - mitos, religião, folclore, artes, hábitos etc. - como uma linguagem, um grande sistema sígnico:

Para a ETM, cultura é memória não-genética, um conjunto de informações que os grupos sociais acumulam e transmitem por meio de diferentes manifestações do processo da vida, como a religião, a arte, o direito (leis), formando um tecido, um "continuum semiótico" sobre o qual se estrutura o mecanismo das relações cotidianas. A cultura é [...] inteligência coletiva, um sistema [...] que molda a dinâmica da vida social, mas leva em consideração não só os aspectos do socius, mas todos os fenômenos que incidem sobre a consciência coletiva. São programas de comportamento que permitem converter acontecimentos em conhecimento (VELHO, 2009, p. 2).

A ligação dos estudos realizados nos seminários com a linguística, vinculada por sua vez a Moscou, moldou o caráter teórico e geográfico da Escola. "A ETM não pode ser pensada nunca em uma relação a uma sede específica. Seu lugar não ocupa o espaço geográfico circunscrito, mas, sim, o espaço das ideias em trânsito" (MACHADO, 2003, p. 45).

Assim, visando encontrar os elementos da cultura que a estruturam com base no uso dos signos e textos, surgiu a Semiótica da Cultura (SC), um campo conceitual e teóricoaplicado formado com a missão de estudar as linguagens na cultura.

Uma das propostas mais importante dentre os achados teóricos da ETM é definição de cultura como texto: toda e qualquer informação, formada de diversos signos que se relacionam - históricos, políticos, estéticos etc. -, transmitida naturalmente nas relações sociais, é organizada em códigos ou textos. "Traduzir um certo setor da realidade em uma das línguas da cultura, transformá-la numa informação codificada, isto é, num texto, é o que introduz a informação na memória coletiva" (MACHADO, 2003, p. 38). A cultura organiza a informação em códigos que são absorvidos e sistematizados no cotidiano. Esses códigos têm a função de culturalizar o mundo, ou seja, dar às informações uma estrutura de cultura.

Pensar a cultura a partir da ideia de estrutura que organiza diversos outros sistemas de códigos só é possível por entender que cada codificação em cada sistema não acontece independente da sua relação com outros sistemas. O texto garante a noção de uma leitura contextualizada, isto é, relacionada a outros sistemas de código e interdependente deles. 
Essa ideia garante outro aspecto importante da SC: a tradução da tradição.

A tradução da tradição pode ser assim compreendida como um encontro entre diferentes culturas a partir do qual nascem códigos culturais que funcionam como programas para ulteriores desenvolvimentos. Nesse caso, os códigos culturais são fontes de gestação da memória nãohereditária, tal como a entendeu Lótman, que se encarrega de formatar os sistemas semióticos da cultura (MACHADO, 2003, p. 30).

Cada código da cultura carece de um entendimento prévio, do indivíduo ou de seu grupo, para que a informação seja estruturada em um novo conhecimento. O contexto, a relação existente entre os dois textos, criam uma nova estrutura cultural. Mas, os contatos fazem com que, mesmo os textos que já possuem sentido para um grupo ou indivíduo, possam sofrer algum tipo de reorganização. Ou seja, a tradição persiste, mas sempre diante da possibilidade de ser reconfigurada, gerando novos signos, novos textos e novos sentidos. Para Lótman,

[...] cultura é uma acumulação histórica de sistemas semióticos (linguagens). A tradução dos mesmos textos para outros sistemas semióticos, a assimilação dos distintos textos, o deslocamento dos limites entre os textos que pertencem à cultura e os que estão além dos seus limites constituem o mecanismo da apropriação cultural da realidade. A tradução de uma porção determinada da realidade para uma das linguagens da cultura, sua transformação em texto, ou seja, em informação codificada de certa maneira, a introdução de tal informação na memória coletiva: esta é a esfera da atividade cultural cotidiana (LÓTMAN apud VELHO, 2009, p. 254).

A rigor, para o autor russo, cultura é memória, por ser sempre acúmulo de textos:

Los aspectos semióticos de la cultura [...] se desarrollan, más bien, según leyes que recuerdan las leyes de la memoria, bajo las cuales lo que pasó no es aniquilado ni passa a la inexistência, sino que, sufriendo una selección y una compleja codificación, passa a ser conservado, para, en determinadas condiciones, de nuevo manifestarse (LÓTMAN, 1998, p. 153).

A tradução da tradição cria constantemente novos sistemas culturais que não estão submetidos aos prévios, mas apropriam-se deles para gerar novas significações. Esses movimentos são um mecanismo fundamental para compreender as semioses na cultura, sobretudo o caráter dinâmico dos textos culturais. 
Também central para as teorias da ETM foi a noção de sistema modelizante.

Por sistemas modelizantes entendem-se as manifestações, práticas ou processos culturais cuja organização depende da transferência de modelos estruturais, tais como aqueles sob os quais se constrói a linguagem cultural. Carente de uma estrutura, o sistema modelizante de segundo grau busca estruturalidade na língua, que somente nesse sentido pode ser considerada sistema modelizante de primeiro grau. Assim considerados, todos os sistemas semióticos da cultura são modelizantes uma vez que todos podem correlacionar-se com a língua (MACHADO, 2003, p. 49).

Se os sistemas culturais são considerados modelos que explicam o mundo, são baseados primeiramente na língua natural, organizadora inicial dos outros sistemas, portanto de primeiro grau. Todas outras manifestações culturais, seus produtos ou ritos, são, portanto, organizados como uma linguagem (texto), logo de segundo grau. Em suma, a ideia de modelização, "no campo da cultura, passa a designar processos de regulação de comportamento dos signos para construir sistemas" (RAMOS et al., 2007, p. 29).

Esses pressupostos colocam a cultura como dinâmica, em mudança a partir da sua relação com novas fontes de informação, que se estrutura em múltiplas gerações a partir da língua e cria modelos culturais de significação que organizam as relações humanas.

\section{A semiosfera}

Entre os representantes da Escola, destaca-se o pesquisador Iuri Lótman, coordenador dos seminários de verão e autor das principais publicações de Tártu. Teve como professor o formalista Vladimir Propp e iniciou carreira na Universidade de Tártu. Entre suas ideias de destaque, oriundas das discussões Seminários de Verão, está a possibilidade de interpretar o espaço semiótico como uma semiosfera. Baseado na ideia de biosfera - conjunto de ambientes terrestres onde os serem vivos interagem, composto por cada ecossistema diferente do planeta - Lótman transfere o princípio para o estudo da cultura. "A semiosfera funciona como a biosfera, aquele ambiente com características específicas e elementos disponíveis para serem acessados e dar condições à vida, à cultura" (VELHO, 2009, p. 7).

A semiosfera é o ambiente onde os signos se relacionam e constroem linguagens e sentidos. É uma instância produtiva em que códigos, linguagens e textos estão mergulhados 
em diversos níveis de interação. "Ela pode ser vista como um ambiente no qual diversas formações semióticas se encontram imersas em diálogo constante [...]. Não é por acaso que uma das imagens mais utilizadas para representar esse espaço seja justamente uma imagem biológica” (RAMOS et al., 2007, p. 34).

Assim se cria a imagem de algo vivo, complexo, organizado dentro de si e, concomitantemente, em interações com outros sistemas em relações operativas de interdependência. Em outras palavras, semiosfera é um conjunto de sistemas culturais que se aproximam e criam laços, fazem trocas, mas subsistem com organizações próprias, ao mesmo tempo que se transformam ao interagir com outros sistemas. A semiosfera garante "a diversidade dos sistemas culturais que a compõem, pois, cada cultura opera dialogicamente frente às demais, contaminando essas e aquelas e permitindo-se contaminar por outras" (RAMOS et al., 2007, p. 35).

$\mathrm{Na}$ definição de Lótman (1996, p. 12), “todo el espacio semiótico puede ser considerado como un mecanismo único (si no como un organismo). Entonces resulta primario no uno o otro ladrillito, sino el 'gran sistema', denominado semiosfera".

Ainda, segundo o autor, dentro da dinâmica inerente à semiosfera, há uma distinção entre o centro do sistema e suas regiões periféricas. O núcleo guarda o enrijecimento daquele sistema cultural, sua autodescrição e suas características mais estáveis. Nas bordas estão maiores ações de troca e transformação, onde contatos com outros sistemas culturais possibilitam maior atividade semiótica e menor estabilidade. O centro também se relaciona com a fronteira e é nessas interações que ocorrem renovações e o surgimento de novas formas culturais. Essa assimetria é, possivelmente, a mais importante característica da semiosfera, conforme Lótman.

$\mathrm{Na}$ região periférica, onde se dá a contaminação de um sistema cultural por outro, se estabelecem encontros dialógicos entre os elementos estruturais das diferentes culturas, dos diferentes sistemas. Os textos mais próximos das bordas têm estrutura mais frágil, estão mais aptos a se "contaminar" e exercer influência, possibilitando situações para o surgimento de novos textos, diferente do que ocorre no núcleo da semiosfera. "Os elementos homogêneos na fronteira entre os sistemas permitem a hibridização, o diálogo, e os heterogêneos vão se conformar oferecendo a possibilidade de novos textos, novas composições com novos significados" (VELHO, 2009, p. 8).

Mais do que linhas demarcatórias ou limites exatos e rígidos, as fronteiras são espaços tradutórios que unem as diferentes estruturas para o nascimento de novos textos, e para a transformação dos existentes. "É pela fronteira que se torna possível apreender as 
trocas informacionais operacionalizadas entre sistemas sígnicos" (RAMOS et al., 2007, p. 38). Dentro da esfera semiótica nenhum sistema de signo está fechado. A semiosfera é um espaço de tensão permanente, onde as estruturas culturais estão em constante transformação.

La frontera del espacio semiótico no es un concepto artificial, sino una importantísima posición funcional y estructural que determina la esencia del mecanismo semiótico de la misma. La frontera es un mecanismo bilingüe que traduce los mensajes externos al lenguaje interno de la semiosfera y a la inversa (LÓTMAN, 1996, p. 13-14).

Esse encontro dado nas zonas de fronteira das esferas semióticas é que permite a tradução de linguagens entres as culturas que se encontram. Essas, por sua vez, vão criar uma nova semiosfera, com novos textos, resultantes das traduções. Por isso, as linguagens modelizantes criadas na cultura não estão separadas inteiramente umas das outras. É necessário o contexto, o dialogismo que irá permitir a tradução de textos e códigos em novos textos e novos códigos, portanto, criando uma nova cultura.

Para compreender a cultura como semiosfera, e, portanto, como diálogo entre linguagens e textos gerados pelo sistema de signos, temos que entender que a fronteira responde justamente pela possibilidade de um espaço comunicar-se com o outro, codificando de modo estranho a uma semiosfera dada. A cultura, então, cria sua organização interna e igualmente seu tipo de desorganização externa, que, graças à fronteira, pode ser absorvida, de modo que $\mathrm{p}$ que parecia choque pode se transformar em encontro e resultar em produção de inusitados sistemas de signos, códigos, textos e linguagens, isto é, em uma nova informação, reforçando o dinamismo, o dialogismo e o continuum cultural (NUNES, 2011, p. 20).

Nas bordas da semiosfera acontecem todos os processos de mediação ou de tradução entre culturas, pois é nesse espaço em que são apreendidos os códigos que serão arranjados em novos textos. Por meio da modelização essa interferência dá forma a novos conjuntos de signos, que se transformaram em uma nova linguagem. Esse é o movimento dinâmico da cultura proposto pela semiosfera. 


\section{O nerd na cultura midiática}

Em 2010, o Dicionário Aurélio ${ }^{3}$ ganhou um novo verbete: nerd. A palavra, que não era estranha na língua portuguesa, abriu espaço em meios mais formais de definição de vocábulos. Em uma procura em sites de busca na Internet, o termo define pessoas interessadas em tecnologia, com inteligência acima da média, facilidade para estudos e interesse em aspectos fantásticos da cultura pop (heróis, ficção científica e fantasia). Nos Estados Unidos, onde a palavra surgiu, está diretamente ligada ao mesmo significado.

A origem do termo está associada à língua inglesa e é sinônimo de bore, dork, $d w e e b$ ou loser (em tradução literal: chato, bobo, panaca ou perdedor). Apesar do termo não ter tradução no português, pode significar literalmente "estranho" ou "desajeitado". No Brasil, a mesma ideia já foi associada ao acrônimo $\mathrm{CDF}^{4}$ há algum tempo.

O primeiro uso documentado da palavra foi no ano de 1950, em um livro do cartunista e escritor americano Dr. Seuss ${ }^{5}$, como nome de um personagem considerado estranho/diferente dentro do contexto da narrativa. Existe outra explicação para a origem da expressão, na qual "seu uso como gíria parece datar de 1951, quando a revista Newsweek reportou seu uso popular como sinônimo de pessoa 'quadrada' ou desinteressante" (FERNANDES; RIOS, 2011, p. 5). Outra versão relaciona seu uso a funcionários de um laboratório: "Datam a origem do grupo a partir da década de 1950, com os trabalhadores dos laboratórios do Northern Electric Research and Development, cuja abreviação é N.E.R.D." (SILVA, 2016, p. 20).

Porém, para além da origem do termo, a definição da palavra nerd ganhou novos significados e se transformou com o decorrer do tempo. Entre suas características principais, o interesse pela ciência e pela tecnologia e o consumo de cultura pop são aspectos que permanecem. Entretanto, outras distinções desse grupo, como a marginalidade dos consumidores dos produtos típicos e o comportamento antissocial e atrapalhado, parecem estar se modificando. Na cultura pop, é possível perceber essa transformação em produtos que tiveram os nerds e/ou sua cultura como temas principais. Personagens nerds foram apresentados ao público de televisão nos Estados Unidos pelo programa Saturday Night

${ }^{3}$ Disponível em: http://g1.globo.com/tecnologia/noticia/2010/09/aurelio-ganha-nova-versao-com-verboscomo-tuitar-e-blogar.html. Acesso em: 01 dez. 2016.

${ }^{4}$ Crânio ou cabeça-de-ferro.

${ }^{5}$ Pseudônimo de Theodor Seuss Geisel (1904-1991), escritor e cartunista norte-americano que lançou mais de 60 livros infantis e ganhou o Oscar de melhor Documentário em 1947. 
Live ${ }^{6}$. Na década de 1980, o ator Bill Murray interpretou, em um dos quadros, um jovem desajustado que passava por situações constrangedoras.

Os atributos físicos e indumentárias característicos dos personagens reapareceram em um filme de 1984, o Revange of the Nerds (A Vingança dos Nerds), que apresentou o mesmo estereótipo inaugurado por Bill Murray. Na narrativa, os calouros da universidade membros da fraternidade ${ }^{7}$ Lambda Lambda Lambda ${ }^{8}$ eram representados com todos as mesmas características físicas e psicológicas e, no desenvolvimento da trama, eram colocados em conflito com outro grupo de universitários: os esportistas, mais adequados aos padrões de beleza do período, portanto, mais "populares". Conforme destaca Santos (2014, p. 27), "filmes como A Vingança dos Nerds (The Revenge of the Nerds, 1984) procuravam enquadrar os nerds no modelo hegemônico de masculinidade da época. Daí o embate constante com figuras como o esportista, o popular ou o valentão".

A dicotomia a partir desses dois estereótipos formou uma percepção geral sobre o que era ser nerd. No filme, os personagens desajustados se destacavam pela inteligência e apresentavam poucos atributos físicos.

Não por acaso, A vingança dos nerds é ambientado em uma universidade. Isso porque, nesse momento, a imagem do nerd estava quase que exclusivamente vinculada ao ambiente acadêmico/escolar. Ao longo da década de 1980 e das subsequentes, em quase todos os níveis de ensino, tirar ótimas notas ou ser muito introvertido era, em muitos casos, o bastante para ser visto como um nerd (YOKOTE, 2014, p. 17).

Como o filme reforçava, esse grupo sempre apareceria de forma negativo, pouco interessante socialmente, marginalizado pelos colegas e sem identificação com os pares.

Na sequência, ainda nos anos 1980, outras produções procuraram dar destaque à figura do nerd e ao embate com os estudantes "populares", se opondo a eles ou tentando um espaço junto ao grupo. É o caso do filme Gatinhas e Gatões (Sixteen Candles, 1984), que "retrata o aniversário de 16 anos da personagem principal (a idade das debutantes na cultura norte-americana), além das constantes tentativas frustradas do grupo de nerds [...]

${ }^{6}$ Série televisiva de grande sucesso nos EUA no ar desde 1975. O programa gira em torno de uma série de quadros que parodiam a cultura e a política americana. Diversos atores de Hollywood foram lançados pelo programa, entre eles, Dan Aykroyd, Jimmy Fallon, Will Ferrell, Eddie Murphy, Bill Murray e Adam Sandler.

${ }^{7}$ Fraternidades de estudantes são comuns em universidades e faculdades nos Estados Unidos. As instituições datam de 1770. A mais antiga registrada é a Chi Phi, na Universidade de Princeton. Comumente as associações incluem diversas atividades intelectuais, filantrópicas, esportivas e de entretenimento.

${ }^{8}$ A Lambda Lambda Lambda ( $\Lambda \Lambda \Lambda$ ou Tri-Lambs) foi uma fraternidade fictícia até o ano de 2006, quando foi fundada, inspirada no filme que a deu origem, na Universidade de Connecticut. 
ter contato com garotas e com o mundo adulto (SANTOS, 2014, p. 22). Em Weird Science (Mulher Nota 1000, 1985), outro sucesso nesse período, “dois garotos sem amigos e nenhum traquejo social, humilhados pelos valentões da escola e ignorados pelas garotas decidem criar sua própria mulher ideal com a ajuda de um programa de computador" (SANTOS, 2014, p. 23).

Os temas tecnologia, relacionamentos e deslocamento social se repetiam nos filmes da década de 1980, casos de Can't Buy me Love (Namorada de aluguel, 1987) e Three O’Clock High (Te Pego Lá Fora, 1987). Neste, o personagem principal, Jerry Mitchel, tem de enfrentar o bully da sua escola que agendou para o fim da aula uma briga. Entre outros exemplos, os filmes representavam personagens que passavam pelos mesmos problemas, com aparência e gostos semelhantes, repetindo os mesmos rituais que se destacam no sistema de High School americano tão popularizado pelo cinema de Hollywood.

O cinema, juntamente com a televisão, serviu com grande força para difundir essa identidade pelo mundo. A figura do nerd não emergiu no cinema ou na TV, mas esses dispositivos ajudaram a propagar amplamente as suas características. Os meios de comunicação de massa têm a força para criar e distribuir esses conteúdos.

As narrativas audiovisuais, além de produtos da indústria de entretenimento, podem ser pensadas como representações de práticas sociais e, nas mídias, como mobilizadoras e formadoras de identidades. Esses meios e seus produtos constituem uma força capaz de emergir a imaginação em um mundo novo. Segundo Edgar Morin (1970, p. 242), “abarca o real, o irreal, o presente, o vivido, a recordação e o sonho, a um nível mental comum". Assim, a figura, o consumo, a personalidade, em resumo, a identidade nerd se desenvolveu e se espalhou pelo mundo, empurrada pela indústria do entretenimento, criando identificações pelo planeta.

Já no início dos anos 2000, outras figuras apareceram evocando características difundidas pela idiossincrasia desse grupo e ampliando a imagem e tipos que compõem a figura nerd. Como produtos de grande repercussão midiática pode-se destacar duas obras: a série de televisão The Big Bang Theory (TBBT) e a franquia de cinema - baseada em obras de história em quadrinhos - Universo Cinematográfico Marvel (UCM) ${ }^{9}$.

\footnotetext{
${ }^{9}$ Marvel Cinematic Universe (MCU).
} 
TBBT é uma sitcom ${ }^{10}$ norte-americana, hoje considerada a de maior sucesso e audiência nesse país, com média de 13 milhões de espectadores, e exibida também em outros países. "A série é também sucesso de crítica, está confirmada na grade da emissora CBS até a décima temporada e acumula quarenta e cinco prêmios, entre os quais um Globo de Ouro" (OLIVEIRA, 2016, p. 1).

A série apresenta o dia a dia de quatro cientistas da Calltech $^{11}$ (Sheldon Cooper é físico teórico, Leonard Hofstadter é físico experimental, Rajesh Koothrappali é astrofísico e Howard Wolowitz é engenheiro e astronauta) que têm uma vida mergulhada em elementos característicos da cultura nerd - tecnologia, história em quadrinhos, ficção científica, fantasia - possuem carreiras de sucesso em seus respectivos campos, mas tentam se encaixar em uma vida social ordinária, com problemas de relacionamento, família e atividades sociais e geral.

Os personagens representam uma evolução nos estereótipos, se comparados aos filmes dos anos 1980, sobretudo na indumentária. Mas a maior quebra se dá com a fase da vida exposta na tela. Agora não são mais adolescentes na escola ou universidade, mas sim adultos de sucesso (a menção a grandes feitos na área da física e engenharia de todos eles nos episódios) que, em certa medida, representam o futuro que os personagens de 30 anos atrás buscavam em suas carreiras profissionais.

Outra mudança proposta para a identidade nerd pela série de televisão está ligada aos relacionamentos sociais e amorosos dos membros do grupo. A quinta protagonista do seriado é Penny (único personagem sem um nome, já que Penny costuma representar um diminutivo, e sem sobrenome).

Penny é loira, bonita, usa roupas provocativas e tem uma fala suave, traços que a colocam em contraste direto com seus vizinhos. A personagem não tem nenhum tipo de familiaridade com o mundo nerd em que seus vizinhos estão inseridos. Ela, na verdade, encarna, em muitos episódios, o papel da "loira burra", com sua falta de adequação ao universo no qual os outros personagens estão inseridos (SILVA, 2016, p. 89).

\footnotetext{
${ }^{10}$ Abreviatura da expressão inglesa situation comedy ("comédia de situação", tradução livre), é usada para designar uma série de televisão com personagens comuns em que existem uma ou mais histórias de humor encenadas em ambientes comuns como família, grupo de amigos, local de trabalho. São comuns e de grande sucesso da grade televisiva dos EUA. Tem duração média de 30 minutos. Exemplos recentes incluem Friends, Two and a Half Man, How I Met your Mothere e Modern Family.

${ }^{11}$ Instituto de Tecnologia da Califórnia (California Institute of Technology) é uma universidade privada norteamericana, localizada em Pasadena, comumente citada como uma das melhores universidades na área de tecnologia do mundo. Entre seu alunos, ex-alunos e professores constam 34 ganhadores do Prêmio Nobel. (Disponível em: https://www.caltech.edu/content/caltech-glance. Acesso em: 09 dez. 2016)
} 
A garota loira gera um contraste com seus interlocutores. Ela não faz parte daquele universo e representa uma massa de espectadores que também não tem relação com o mundo nerd, mas que, com o passar do tempo, começaram a adotar, mesmo que sem total entendimento do tema, aquele universo. No decorrer da narrativa, os personagens de Penny e Leonard iniciam e terminam diversas vezes um relacionamento amoroso que culmina com o casamento no final de $8^{\mathrm{a}}$ temporada. Essa relação representa a mudança de paradigma tão almejada pelos personagens nerds da cultura pop do cinema e da televisão. Penny se interessa pelo nerd, apesar de sua estranheza social. Um cartaz de divulgação do seriado mostra no topo da arte, a frase: "Smart is the new sexy" (Inteligência é o novo sexy). The Big Bang Theory dá um novo espaço ao nerd. Eles são estranhos e desajeitados, mas respeitados profissionalmente e interessantes sexualmente. Essa é a nova imagem que busca novas identificações.

Outro exemplo desta mudança da identidade nerd impulsionada pela produção cinematográfica e televisiva está presente no Universo Cinematográfico Marvel.

Em 2008, a empresa iniciou o MCU (Universo Cinematográfico Marvel) com o filme Homem de Ferro (Jon Favreau, 2008), a proposta era de que todos os filmes da empresa a partir de então estivessem conectados em um mesmo universo cinematográfico. As histórias eram entrelaçadas, como por exemplo, em um filme do Homem de Ferro, sempre tinha referências ao filme Thor, obedecendo uma linha do tempo bem definida. Todos os filmes se interligavam de algum modo. Até que houve o estopim, quando foi lançado o filme Os Vingadores (Joss Whedon, 2012) onde todas as histórias se ligavam em um único longa, com os super-heróis de todos os outros filmes lançados avulsamente (GOMES; THEORGA; COSTA, 2016, p. 10).

Além da novidade nas técnicas narrativas do cinema, da mobilização financeira criada pelos filmes e da disponibilização para um grande público, por meio do cinema, dos heróis de histórias em quadrinhos, um dos objetos mais representativos do universo nerd, o MCU apresentou ao mundo um novo perfil de nerd, o personagem Tony Stark. O herói Homem de Ferro/Tony Star é representado por Robert Downey Jr desde seu primeiro filme em 2008. O ator interpretou o personagem em diversas outras películas do Universo Cinematográfico Marvel: O Incrível Hulk (2008), Homem de Ferro 2 (2010), Os Vingadores (2012), Homem de Ferro 3 (2013), Vingadores: A Era de Ultron (2015) e Capitão América: Guerra Civil (2016).

\footnotetext{
${ }^{12}$ Pode ser visualizado em: http://migre.me/vIzbq, acesso em: 09 dez. 2016.
} 
O personagem carismático trouxe o ator de volta ao estrelato tornando-o a principal referência no MCU. Entretanto, por mais que não seja o foco da narrativa, Tony Stark é um nerd. Seus problemas antissociais, manias e compulsões que tendem ao transtorno obsessivo compulsivo (TOC), o amor pela tecnologia e a presença de elementos da cultura pop, como rock'n'roll por exemplo, apareceram no filme sob um novo perfil de nerd: do deslocado socialmente, sobretudo por causa da dedicação, estudo e inteligência, é agora a figura de destaque. 'Ele representa, assim, o 'sonho' daquele que se imagina como sendo o estereótipo do nerd: ser reconhecido por suas capacidades intelectuais, ter habilidades de relacionamentos sociais e amorosos e ser admirado pela sociedade" (SILVA, 2016, p. 43).

Esse novo perfil desloca-se da produção midiática transformando a cultura ao seu redor. O novo caráter é aceito, contestado, debatido e algumas vezes rejeitado. Porém, há sempre ressignificações de conteúdos forçadas por uma nova forma cultural.

\section{Nerd, semiosfera e cultura}

Ao entender a formação da cultura nerd, é possível perceber que ela se baseia em uma variedade de sistemas culturais e que, ao tensiona-la, estabelecem um movimento paradoxal de, por um lado, concretizar figura e identidade do sujeito definido como nerd, e, por outro, abalar as estruturas desse sistema com outros que ajudam a construí-lo e defini-lo. Seu dinamismo se dá nos contatos entre as estruturas e suas contínuas traduções.

Tomado por separado, ninguno de ellos tiene, en realidad, capacidad de trabajar. Sólo funcionan estando sumergidos en un continuum semiótico, completamente ocupado por formaciones semióticas de diversos tipos y que se hallan en diversos niveles de organización (LÓTMAN, 1996, p. 11).

Se pensarmos nas definições de cultura e de semiosfera, é possível entender as dinâmicas de contágio e tradução:

Como semioticamente não-homogênea, composta pela diversidade de sistemas sígnicos que modelizam os textos: texto cultural com funções de comunicação, de geração de sentido e de memória, porque o texto condensa informações, não só recebe informações de fora dele, mas também as ocasiona, e, assim, adquire memória. Na heterogeneidade da semiosfera, o intercâmbio entre os diferentes textos pode ser concebido 
como dialógico. E é neste trânsito que ocorrem as confluências imprevisíveis, criando novas organizações de linguagem, novos textos de cultura (NUNES, 2014, p. 11).

Esse processo dinâmico ocorre da irradiação de diversos textos midiatizados da cultura convergindo numa nova esfera. A cultura nerd é, entre outras coisas, o resultado desse continuum semiótico, em que signos ganham novas codificações e se transformam em novos textos, repletos de outros sistemas e reabastecidos por eles. Uma hibridação ou tradução para criar essa estrutura que, em si mesma, ganha reorganizações contínuas através do tempo. "La reserva de textos, códigos y distintos signos que se precipita de la vieja cultura a la cultura nueva, más joven [...] se deposita en la memoria cultural de la colectividad como un valor auto-suficiente" (LÓTMAN, 1996, p. 36).

Tal diferenciação faz parte do processo de cultura, e os produtos culturais exprimem esse dinamismo. Há nesse movimento um retrato equivalente ao apresentado nas discussões sobre o continuum chamado de semiosfera: "espaço abstrato, mas não metafórico, onde vivem os signos na cultura; espaço semiótico em que se produzem os processos comunicativos e novas informações e fora do qual não há semiose, ação do signo" (NUNES, 2014, p. 10).

A renovação do caráter explicito da figura do nerd é sinal do dinamismo que os textos apresentam na semiosfera. A aproximação com outras estruturas que criam ressignificações dessa identidade demonstra esses trânsitos. Os dispositivos de criação na memória coletiva incorporam, entre outros, os códigos e textos midiáticos, como no caso da cultura nerd, para se estabelecer como um texto comum, incluindo o próprio corpo dos personagens e as identidades neles construídas. "Pelo corpo, o texto narrativo midiático cresce por si mesmo, transformado pela invenção dos materiais e de outro tempo que o condiciona. Feito de novas materialidades, propulsor de novos sentidos, torna-se, então, texto-memória expandindo-se no espaço semiótico" (NUNES, 2014, p. 15).

Lótman define cultura como sistema não-homogêneo, composto pela diversidade de textos que dialogam para a criação de novos textos e sentidos, todos modelizados pela linguagem da cultura. Por isso, o nerd e seus aspectos culturais - definidos em seus ritos, personagens, imaginários e práticas - configuram-se dentro dessa noção, pois realizam um intercâmbio dialógico entre seus textos e códigos.

A figura do nerd não tem lugar nem perfil estáticos, mas se reconfigura e ganha novas roupagens por meio desses mecanismos semióticos ancorados na semiosfera da cultura midiática, que interpela linguagens de outras esferas, assim como faz circular 
seus textos da fronteira para o núcleo e vice-versa em constante movimento. "Tal como o diálogo, a assimetria é um mecanismo da cultura que diz respeito a esta circulação de textos, ao traslado de um sistema de codificação a outro" (NUNES, 2014, p. 11). Dessa maneira, a concepção dinâmica que se tem sobre a cultura pode modificar-se estruturalmente, ganhando nova aparência, e, posteriormente, repetir essa ação, a partir de novos textos.

\section{Considerações finais}

O trabalho da SC é, grosso modo, "examinar os complexos sistemas de signos que estão modelizados sob forma de texto" (RAMOS, 2007, p. 33). Nessa medida, este trabalho teve como objetivo refletir acerca dessa teoria, em especial da noção de semiosfera, e de como seus conceitos podem ser utilizados para a entender a cultura nerd, na tessitura dos textos culturais midiáticos.

Não cabe aqui engendrar conclusões sobre a cultura, mas sim, afirmar que o nerd e seus textos (personagem, comportamento, ideário, consumo, lazer etc.) apresentados na mídia de massa (HQ, cinema e TV) representam uma esfera semiótica, que se estrutura em si mesma, e no contato produtivo com outras esferas que traduzem, modificam e transformam suas linguagens e sentidos, num continuum semiótico, através do tempo. Daí a importância de uma noção de cultura que privilegie o dinamismo e os trânsitos semióticos dos seus objetos.

\section{Referências}

ADORNO, T. W. O Fetichismo na Música e a Regressão da Audição. In: Textos Escolhidos (Os Pensadores). 3. ed. São Paulo: Nova Cultural, 1989, p. 79-105.

FERNANDES, L. F.; RIOS, R. Enciclonérdia. São Paulo: Panda Books, 2011.

GOMES, C. O.; THEORGA, F. D. S.; COSTA, R. R. A invasão das HQ's no mundo televisivo e cinematográfico - uma análise culturológica e transmidiática das produções de super-heróis da Marvel e DC. In: CONGRESSO BRASILEIRO DE CIÊNCIAS DA COMUNICAÇÃO INTERCOM. 39., 2016. Anais [...]. São Paulo-SP: USP, 2016. 
LÓTMAN, I. M. La semiosfera I. Semiótica de la cultura y del texto. Madrid/Valencia: Ediciones Cátedra/Frónesis Universidad de Valencia, 1996.

LÓTMAN, I. M. La semiosfera II. Semiótica de la cultura, del texto, de la conducta y del espacio. Madrid/ Valencia: Ediciones Cátedra/Frónesis Universidad de Valencia, 1998.

MACHADO, I. Escola de semiótica: a experiência de Tártu-Moscou para o estudo da cultura. São Paulo: Ateliê Editorial/ FAPESP, 2003.

MORIN, E. O cinema ou o homem imaginário. Lisboa: Moraes Editores, 1970.

NUNES, M. R. F. Passagens, paragens, veredas: semiótica da cultura e estudos culturais. In.: SANCHES, T. A. (org.). Estudos culturais: uma abordagem prática. São Paulo: SENAC, 2011, p. 13-38.

NUNES, M. R. F. A emergência da cena cosplay nas culturas juvenis. Significação: Revista de Cultura Audiovisual. São Paulo, v. 41, n. 41, p. 218-235, 2014.

OLIVEIRA, E. F. Smart is the new sexy: a ressignificação do nerd na sitcom The Big Bang Theory. In: In: CONGRESSO BRASILEIRO DE CIÊNCIAS DA COMUNICAÇÃO - INTERCOM. 39., 2016. Anais […]. São Paulo-SP: USP, 2016.

RAMOS, A. V. et al. Semiosfera: exploração conceitual nos estudos semióticos da cultura. In: MACHADO, I. (org). Semiótica da cultura e semiosfera. São Paulo: Annablume/Fapesp, 2007, p. 27-44.

SANTOS, P. M. O nerd virou cool: consumo, estilo de vida e identidade em uma cultura juvenil em ascensão. Dissertação (Mestrado em Comunicação). Programa de Pós-Graduação em Comunicação da Universidade Federal Fluminense, Niterói-RJ, 2014.

SILVA, S. M. Is nerd the new sexy? Um estudo sobre a recepção da série televisiva The Big Bang Theory. Dissertação (Mestrado em Comunicação). Instituto de Cultura e Arte, Universidade Federal do Ceará, Fortaleza-CE, 2016.

VELHO, A. P. M. A semiótica da cultura: apontamentos para uma metodologia de análise da comunicação. Revista de Estudos da Comunicação, Curitiba, v. 10, n. 23, p. 249-257, set./dez. 2009. 
YOKOTE, G. K. L. O mundo dos nerds: imagens, consumo e interação. Dissertação (Mestrado em Antropologia Social). Faculdade de Filosofia, Letras e Ciências Humanas da Universidade de São Paulo, São Paulo-SP, 2014.

1 Professor do Programa de Pós-Graduação em Comunicação da Universidade Metodista de São Paulo - UMESP. Doutor em Comunicação e Semiótica pela PUC-SP. E-mail: heromvargas50@gmail.com.

${ }^{2}$ Professor da Universidade Estadual de Minas Gerais e doutorando no Programa de Pós-Graduação em Comunicação da Universidade Metodista de São Paulo - UMESP. E-mail: anderson_arocha@yahoo.com.br. 